The $14^{\text {th }}$ World Conference on Earthquake Engineering

October 12-17, 2008, Beijing, China

\title{
AN ASSESSMENT OF DAMAGE POTENTIAL AND OF BUILDING PERFORMANCE DEMANDS FOR ROMANIAN VRANCEA EARTHQUAKES
}

\author{
I.-G. Craifaleanu ${ }^{1}$ and D. Lungu ${ }^{2}$ \\ ${ }^{1}$ Associate Professor, Dept. of Reinforced Concrete Structures, Technical University of Civil Engineering \\ \& National Institute for Building Research, Bucharest, Romania \\ Email: iolanda@incerc2004.ro,i.craifaleanu@gmail.com \\ ${ }^{2}$ Professor, Dept. of Reinforced Concrete Structures, Technical University of Civil Engineering \\ \& National Institute for Historical Monuments, Bucharest. Romania
}

\begin{abstract}
:
Damage spectra, based on the Park-Ang damage index, DM, were generated, for Vrancea events with moment magnitude larger than 6.0. Strength demand spectra were also computed, in order to assess the strength capacity required to limit the damage index to a specified (target) value. The resulted strength demands were then mapped, for several values of $D M . \mu_{u}$, and of structural period. Some applications of the approach, from the structural engineering point of view, were shown.
\end{abstract}

KEYWORDS: damage index, Vrancea earthquakes, damage spectra, maps of strength demands

\section{INTRODUCTION}

Damage indices can provide valuable information in evaluating the building damage potential of ground motions. A more recently used approach is the mapping of damage spectra ordinates (Bozorgnia and Bertero, 2001). This has proved to give useful information in assessing the spatial distribution of damage for a given earthquake and for buildings with specified strength and stiffness characteristics.

One of the most widely used indices is the Park-Ang damage index (Park and Ang, 1985). The index is defined by the following relationship:

$$
D M=\frac{u_{\max }}{u_{u}}+\beta \frac{E_{H}}{F_{y} u_{y}}
$$

where

$u_{\max }=$ maximum deformation demand during the ground motion

$u_{u}=$ ultimate deformation capacity of the system under monotonically increasing lateral deformation

$E_{H}=$ hysteretic energy

$F_{y}=$ yield strength

$\beta=$ constant depending on structural characteristics.

As one can observe from Eqn. 1.1, DM takes into account both the damage due to the maximum deformation attained during the ground motion and the damage due to repeated cycles of inelastic deformation. According to experimental results and field observations in earthquakes, $\beta$ can be taken as equal to 0.15 (Cosenza et al., 1992; Fajfar, 1992).

The conventional interpretation of $D M$ values is the following: $D M=0.4$ is considered as the upper limit of repairable damage; values between 0.4 and 1.0 characterize non-repairable damage, while values larger than 1.0 correspond to failure (Teran-Gilmore, 1996). 
The $14^{\text {th }}$ World Conference on Earthquake Engineering

October 12-17, 2008, Beijing, China

The Park-Ang damage index has some drawbacks that have been pointed out in the literature (Bozorgnia and Bertero 2001). For instance, for elastic response, when $E_{H}$ is 0 and the damage should be zero, the value of $D M$ is greater than zero Moreover, the index does not provide correct results for a system subjected to monotonic deformation. However, $D M$ it is still largely used for different applications due to its simplicity and its experimental validation.

By writing the expressions of displacement ductility, $\mu$, ductility under monotonically increasing lateral deformation, $\mu_{u}$, and equivalent ductility (Mahin and Bertero, 1981), $\mu_{E}$ :

$$
\begin{gathered}
\mu=u_{\text {max }} / u_{y} \\
\mu_{u}=u_{u} / u_{y} \\
\mu_{E}=1+E_{H} /\left(F_{y} u_{y}\right)
\end{gathered}
$$

it results from Eqn. 1.1 that $D M$ can be expressed as a function of the three ductilities above:

$$
D M=\frac{\mu}{\mu_{u}}+\beta \frac{\mu_{E}-1}{\mu_{u}}
$$

or

$$
D M \cdot \mu_{u}=\mu+\beta\left(\mu_{E}-1\right)
$$

The use of the product $D M . \mu_{u}$ instead of $D M$ was considered as more convenient for the present study, as it separates on the right-hand side of Eqn. 1.6 the values corresponding to alternate loading. Therefore, throughout the paper, damage is expressed by using $D M . \mu_{u}$. The interpretation of results is made by considering relevant values of $\mu_{u}$.

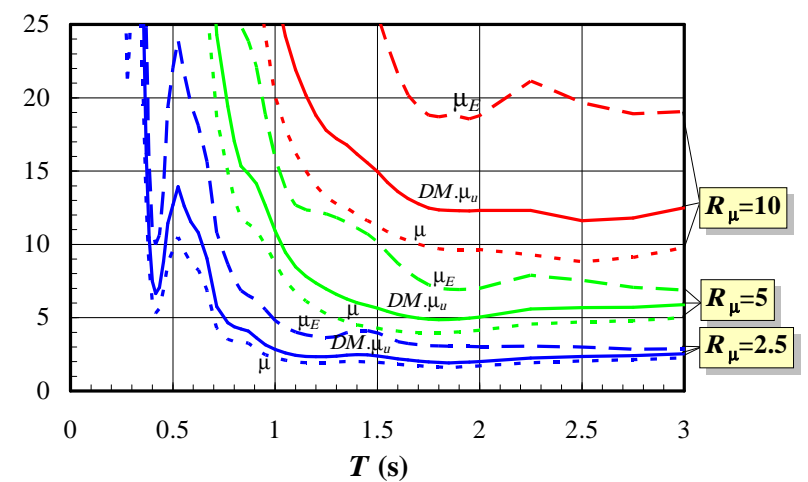

Figure 1. Comparison between the variations of $\mu, \mu_{E}$ and DM. $\mu_{u}$. INCERC, March 4, 1977, NS component

Figure 1 (Craifaleanu, 1998) shows spectra of the product $D M . \mu_{u}$ and of the ductilities $\mu$ and $\mu_{E}$, for the NS component of the ground motion recorded at INCERC during the earthquake of March 4, 1977. Spectra were determined for an elastic-perfectly plastic system with a damping ratio of $5 \%$. The parameter of the curves in Fig. 1 is the strength modification factor, $R_{\mu}$, expressed by

$$
R_{\mu}=F_{e l, \max } / F_{y}
$$

where $F_{e l, \max }$ is the maximum strength demand for the considered ground motion, if the system would behave elastically. 
The $14^{\text {th }}$ World Conference on Earthquake Engineering

October 12-17, 2008, Beijing, China

As one can observe from Fig. 1, the values of $D M . \mu_{u}$ are always situated between those of $\mu$ and $\mu_{E}$. For elastic response, $0 \leq D M . \mu_{u} \leq 1$, while for inelastic response, $D M . \mu_{u}>1$.

\section{DAMAGE SPECTRA}

Damage spectra were calculated for several ground motions recorded during the strong earthquakes of March 4, 1977 (moment magnitude $M_{W}=7.5$, focal depth $\left.h=109 \mathrm{~km}\right)$ and August 30, $1986\left(M_{W}=7.1, h=133 \mathrm{~km}\right)$. Records provided by 35 seismic stations were used. Of these stations, 34 were located in Romania (24 in the INCERC network, 10 in the NIEP network (Seismic Database 2001)) and one was located in the Republic of Moldova (station Chisinau, IGG network). Only the horizontal components of ground motions were taken into account in the study. The total number of analyzed seismic records was 72 , including the two horizontal components of the INCERC Bucharest single record of March 4, 1977.

The spectra were determined by considering a bilinear, elastic-perfectly plastic hysteretic behavior of the SDOF systems, and a damping ratio of $5 \%$. The above hypotheses were used throughout the entire study presented in this paper.

As a parameter of spectral curves, the yield strength coefficient $C_{y}$, was chosen. The coefficient $C_{y}$ can be expressed as

$$
C_{y}=F_{y} / G
$$

where $G$ is the weight of the SDOF system and $F_{y}$ has the same signification as in Eqn. 1.1. The coefficient $C_{y}$ is a simple measure of the yield strength of the system and can be quite easily related to the code-specified base shear coefficient $C_{s}$. By denoting the overstrength factor as $R_{O V}$, the following expression can be written (Craifaleanu, 2005):

$$
C_{y}=C_{s} R_{o V}
$$

For illustration, spectra of the product $D M . \mu_{u}$ are shown in Fig. 2 (Craifaleanu 2001) for the NS component of the March 4, 1977 INCERC record and for different values of $C_{y}$.

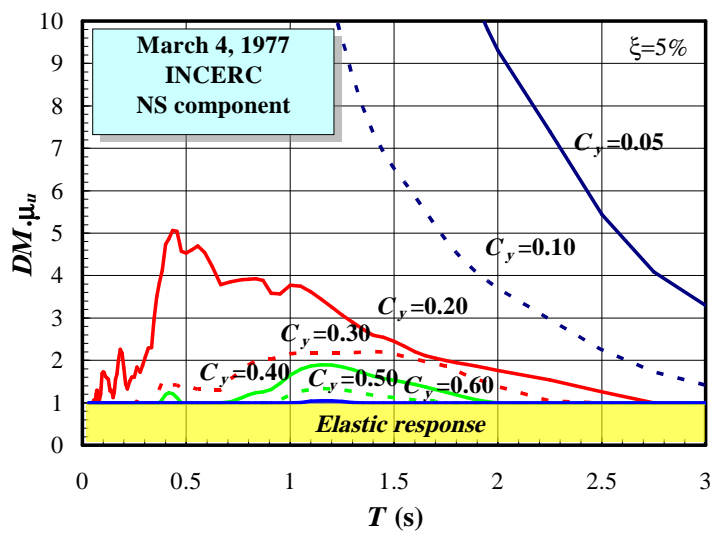

Figure 2. Spectra of the product $D M . \mu_{\mathrm{u}}$, computed for different values of the yield strength coefficient, $C_{y}$.

March 4, 1977, INCERC Bucharest, NS component

As it can be observed from Fig. 2, at short periods, for $\mathrm{C}_{\mathrm{y}}$ values lower than 0.2 (which corresponds to the PGA, in g's, for this record), the values of $D M . \mu_{u}$ are very large. They tend to infinity as SDOF system period and $C_{y}$ 
The $14^{\text {th }}$ World Conference on Earthquake Engineering

October 12-17, 2008, Beijing, China

tend to zero. With the increase of yield strength, the values of $D M . \mu_{u}$ decrease, reaching values below unity for elastic response.

A comparison between the $D M . \mu_{u}$ spectra of several ground motions recorded in Bucharest during the previously mentioned seismic events (Fig. 3) reveals large differences between their damage potential. The largest values of $D M . \mu_{u}$ were obtained, as expected, for the records of 1977. Larger values were also obtained for the 1986 earthquake, at the stations EREN, Otopeni and Magurele, situated in the peripheral, sparsely built area of the city.

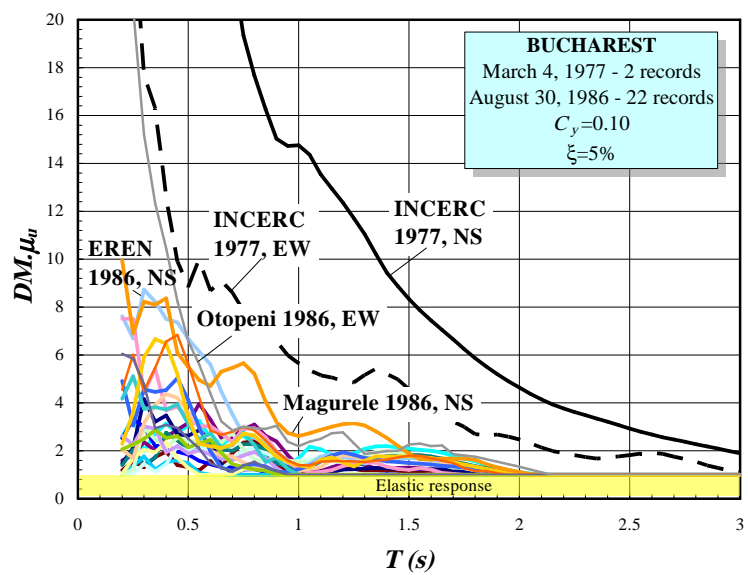

Figure 3. Comparison of DM. $\mu_{u}$ values for the two horizontal components of the INCERC Bucharest record of March 4, 1977 and for 22 Bucharest records of the August 30, 1986 earthquake. $C_{y}=0.10$

\section{STRENGTH DEMAND SPECTRA FOR TARGET VALUES OF DAMAGE INDEX}

An alternate approach in the study of damage indices is to determine the yield strength that would ensure that for buildings with certain characteristics, damage for the considered seismic motion is limited to a desired (target) level, $D M$. For the case of $D M . \mu_{u}$ spectra, this requires that the values of $\mu_{u}$ are specified.

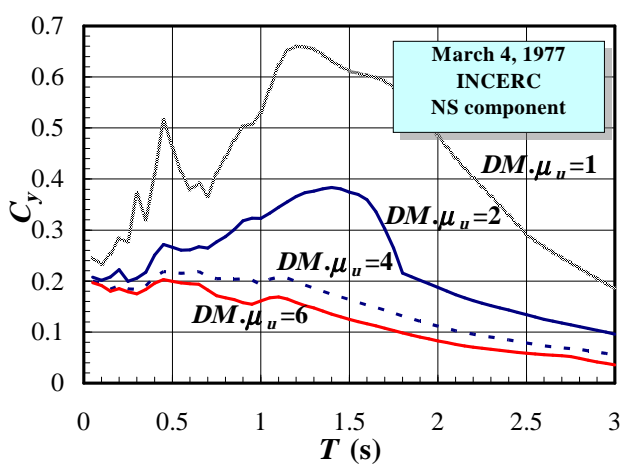

Figure 4. Spectra of $C_{y}$ for different values of $D M . \mu_{u}$. March 4, 1977, INCERC, NS component

For the purpose of the present study, strength demand spectra for a set of relevant values of $D M . \mu_{u}$ were determined for all 72 ground motions analyzed.

Figure 4 shows the strength demand spectrum of the north-south component of the INCERC March 4, 1977 record, computed for four values of $D M . \mu_{u}$, among which the value 1 , corresponding to the upper limit of elastic behavior. One can notice on this diagram the evolution of the shape of the curves with the increase of 
The $14^{\text {th }}$ World Conference on Earthquake Engineering

October 12-17, 2008, Beijing, China

$D M . \mu_{u}$, and the progressive attenuation of the "fingerprint" of the predominant period of the ground motion.

\section{DISTRIBUTION OF YIELD STRENGTH DEMANDS FOR TARGET VALUES OF DM. $\mu_{U}$}

Maps were generated for two values of structure period $T=0.5 \mathrm{~s}$ and $T=1.0 \mathrm{~s}$ and for three values of the product $D M . \mu_{u}$, i.e. 2, 4 and 6. By mapping the $C_{y}$ ordinates for the 35 seismic stations considered, the maps in Figs. 5 and 7 were obtained.

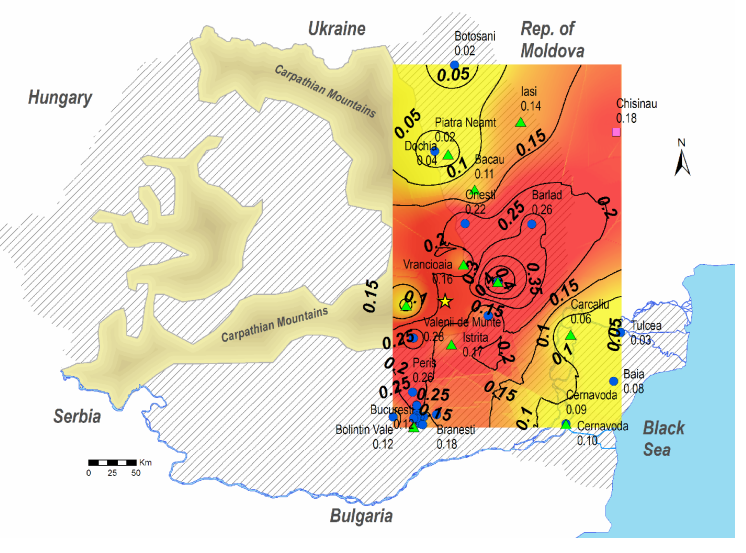

a) $D M . \mu_{u}=2$

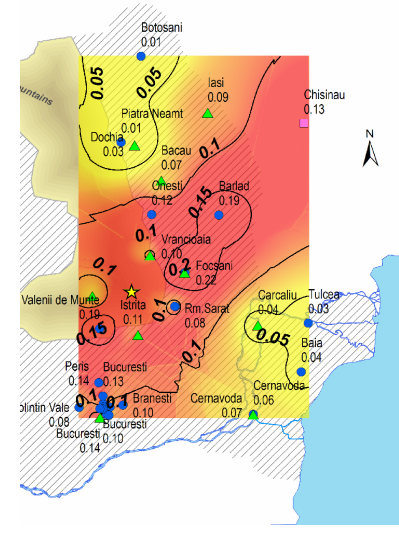

b) $D M . \mu_{u}=4$

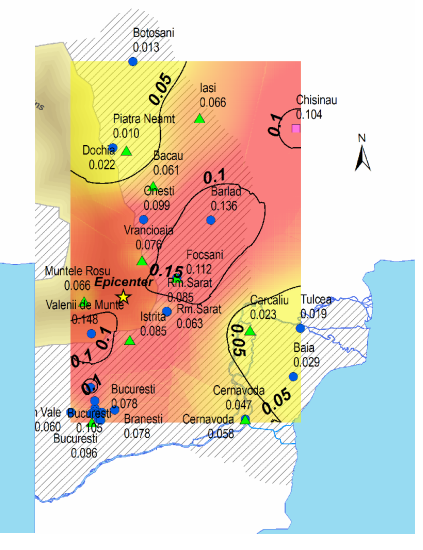

c) $D M . \mu_{u}=6$

Figure 5. Spatial distribution of yield strength demands $\left(C_{y}\right)$ for the Vrancea earthquake of August 30, 1986. Structure period $T=0.5 \mathrm{~s}$

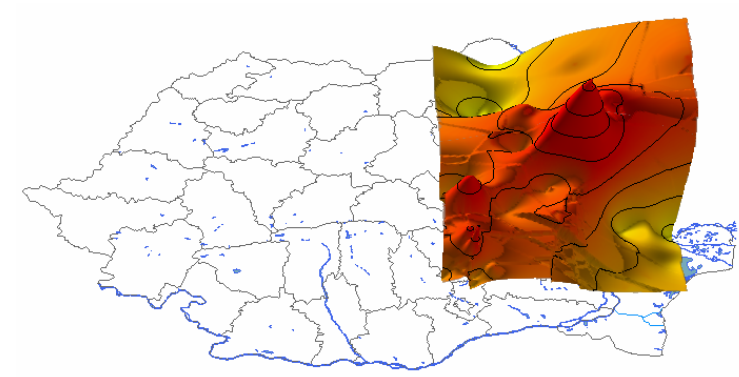

a) $D M . \mu_{u}=2$

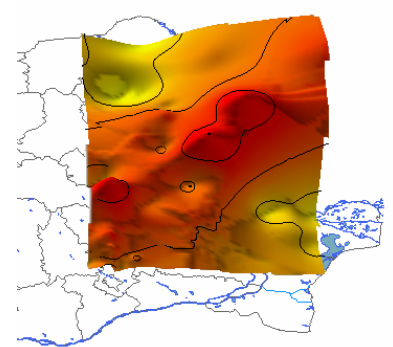

b) $D M . \mu_{u}=4$

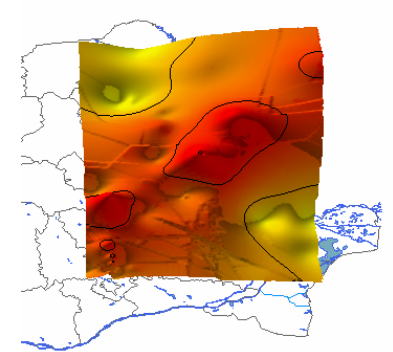

c) $D M . \mu_{u}=6$

Figure 6. Three-dimensional representation of the interpolation surfaces in Fig. 5

To provide a more intuitive image of the spatial distribution of strength demands and of their variation with the target damage level, Figs. 6 and 8 show three-dimensional views of the interpolation surfaces in Figs. 5 and 7.

One of the most distinct features of the maps is the orientation of contours along a northeast-southwest direction. This feature, which was previously observed also on maps generated for other parameters, such as the peak ground acceleration or the spectral acceleration (Craifaleanu et al., 2006; Lungu and Craifaleanu, 2007), corresponds to the results of previous studies concerning the predominant direction of propagation of seismic waves for the August 30, 1986 seismic event.

The $C_{y}$ ordinates calculated for $T=0.5 \mathrm{~s}$ are larger than the values corresponding to $T=1.0 \mathrm{~s}$, as a consequence of the spectral contents of the analyzed records. The spatial variation of $C_{y}$ is more marked for $T=0.5 \mathrm{~s}$ than for $T=1.0 \mathrm{~s}$. 
The $14^{\text {th }}$ World Conference on Earthquake Engineering

October 12-17, 2008, Beijing, China

The most evident consequences of increasing $D M . \mu_{u}$ are the narrowing of the range of variation of the $C_{y}$ ordinates and the general decrease of their values, i.e. the flattening of the interpolation surfaces.

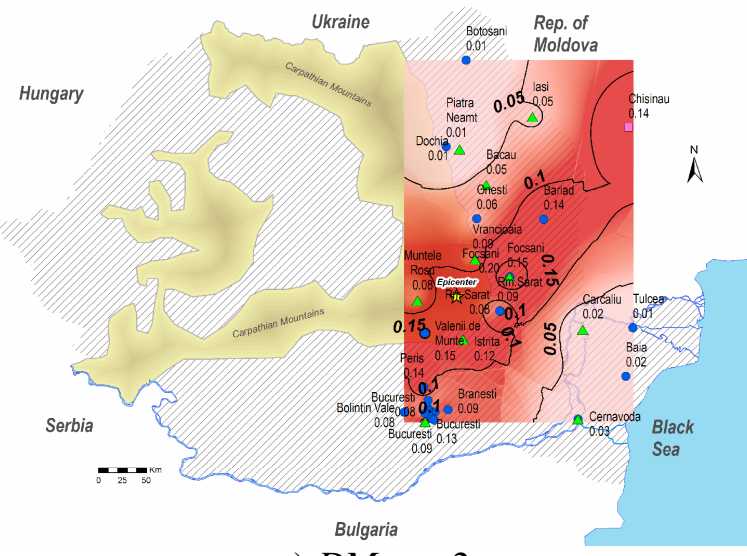

a) $D M \cdot \mu_{u}=2$

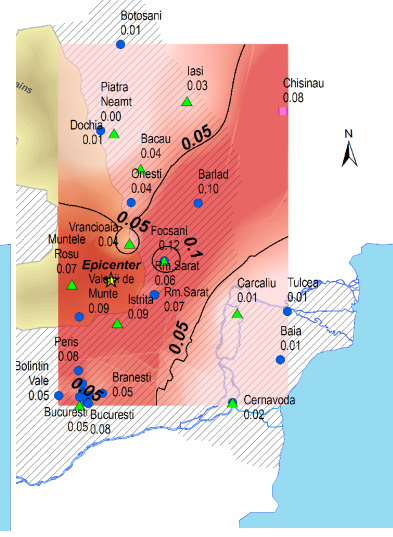

b) $D M \cdot \mu_{u}=4$

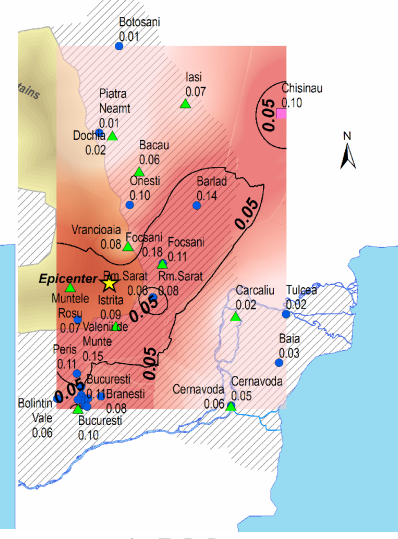

c) $D M \cdot \mu_{u}=6$

Figure 7. Spatial distribution of yield strength demands $\left(C_{y}\right)$ for the Vrancea earthquake of August 30, 1986. Structure period $T=1.0 \mathrm{~s}$

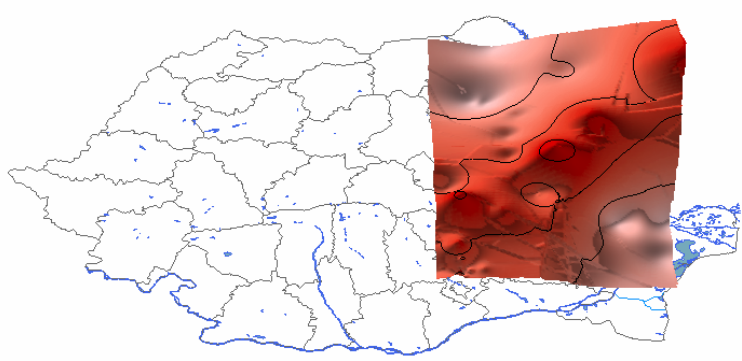

a) $D M . \mu_{u}=2$

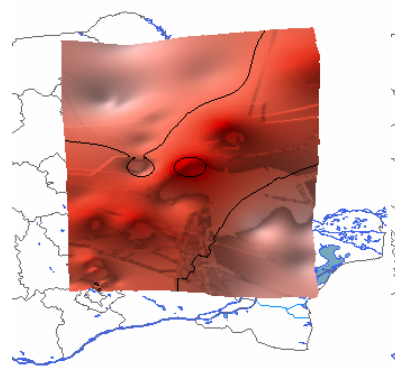

b) $D M . \mu_{u}=4$

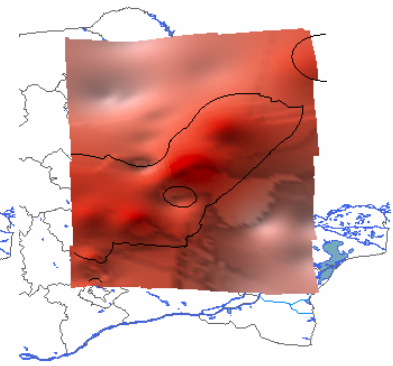

c) $D M \cdot \mu_{u}=6$

Figure 8. Three-dimensional representation of the interpolation surfaces in Fig. 7

The detailed spatial distribution of yield strength demands for the city of Bucharest is shown in Figures 9 and 10 , for the same values of $D M . \mu_{u}$ and of the structure period mentioned above.

As it can be observed on all maps, the larger the accepted value of $D M . \mu_{u}$, the smaller the strength capacity requirements. Also the strength capacity requirements for $T=1.0 \mathrm{~s}$ are less significant, compared with those corresponding to $T=0.5 \mathrm{~s}$.

As for the spatial distribution of the ordinates, the largest $C_{y}$ values occur in the three stations located in the sparsely built zones around the city, i.e. in stations Otopeni, Magurele and EREN, as it was already shown in the previous section of the paper. However, as $D M . \mu_{u}$ increases, the spatial distribution of $C_{y}$ ordinates becomes more and more uniform.

In order exemplify the interpretation of the above maps, a value of $\mu_{u}=6$ is assumed. For the values considered for $D M . \mu_{u}$, it results in $D M=0.33,0.67$ and 1.00. It can then be observed that, in the central area of the city, a damage level corresponding to $D M=0.33$ (in the range of repairable damage) could be obtained by providing the building an overall yield strength equal to $12-17 \%$ of the building weight, for $T=0.5 \mathrm{~s}$ (Fig. $9 \mathrm{a}$ ), and equal to $7-9 \%$ of the building weight, for $T=1.0$ s (Fig. 10 a). For $D M=0.67$, the same values were $8-10 \%$ (Fig. 9 b) 
The $14^{\text {th }}$ World Conference on Earthquake Engineering October 12-17, 2008, Beijing, China

and b 5-6\%, respectively (Fig. 10 b), while for $D M=1.00$, values of 7-8\% (Fig. 9 c) and 4-5\% (Fig. 10 c) were found.

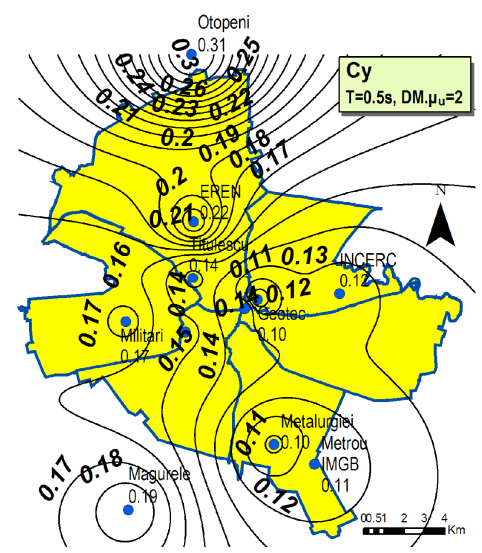

a) $D M . \mu_{u}=2$

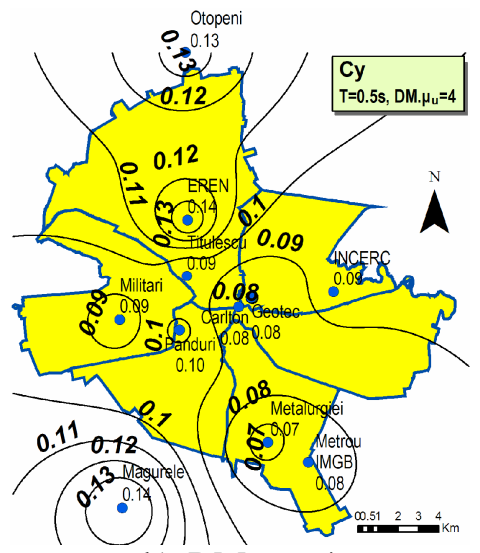

b) $D M . \mu_{u}=4$

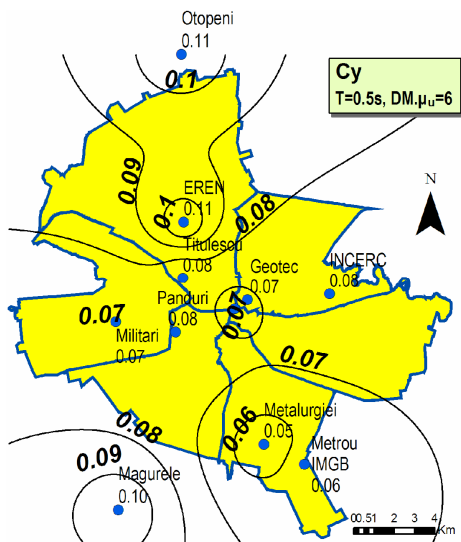

c) $D M \cdot \mu_{u}=6$

Figure 9. Spatial distribution of yield strength demands $\left(C_{y}\right)$ in Bucharest, for the Vrancea earthquake of August 30, 1986. Structure period $T=0.5 \mathrm{~s}$

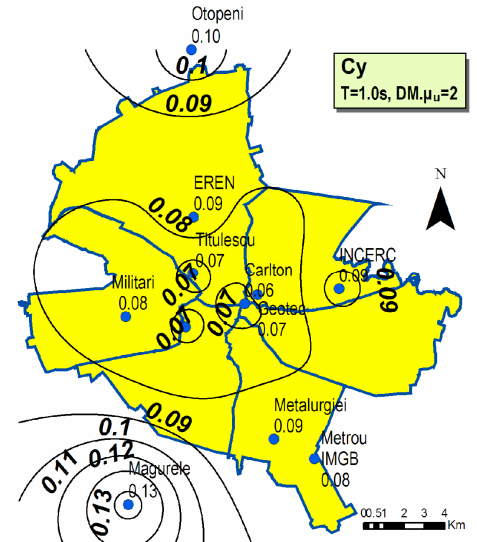

a) $D M . \mu_{u}=2$

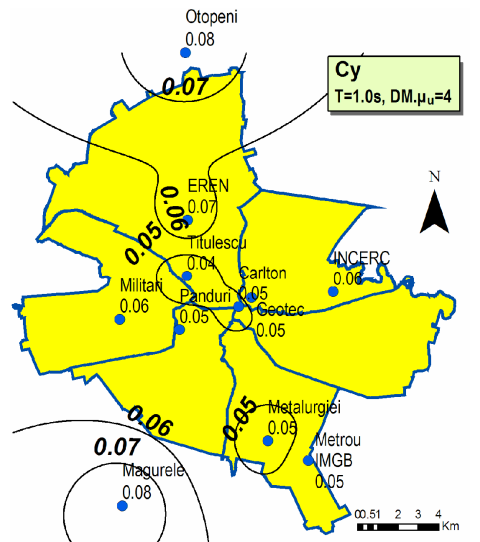

b) $D M . \mu_{u}=4$

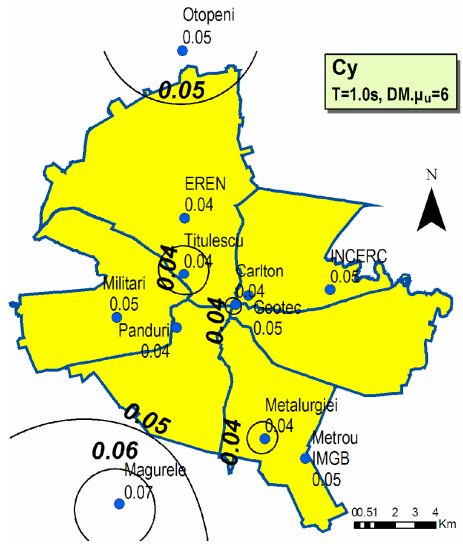

c) $D M . \mu_{u}=6$

Figure 10. Spatial distribution of yield strength demands $(C y)$ in Bucharest, for the Vrancea earthquake of August 30, 1986. Structure period $T=1.0 \mathrm{~s}$

The above results should be correlated with the typology, characteristics and spatial distribution of the building stock in Bucharest. Also, the limitations of the damage index considered and of the SDOF model used in the calculations, as compared to the actual MDOF models, should be taken into account.

\section{CONCLUDING REMARKS}

The paper presented some possible applications of damage indices in estimating the damage potential and the building performance demands of seismic ground motions. Spectra and maps of yield strength demands were generated for records of strong Romanian Vrancea earthquakes, taking into account different values of a target damage index. The study focused particularly on the earthquake of August 30, 1986, the strongest seismic event for which distributed records were available. Despite the relatively small number of stations which provided data, interesting conclusions could be drawn. The mapping of strength demand spectral ordinates showed a spatial distribution pattern which is consistent with that obtained by the authors in previous mapping studies of 
The $14^{\text {th }}$ World Conference on Earthquake Engineering

October 12-17, 2008, Beijing, China

ground motion parameters and of linear/nonlinear spectra. Also, it was shown that, for higher target (acceptable) damage levels, strength demands decrease and, furthermore, their spatial variation attenuates. Hence, in this case, the influence of structural behavior tends to prevail over that of ground motion characteristics.

Strength demand spectra, determined for specified (target) values of the damage index, appear to represent a more complex and promising way for assessing seismic demands, as compared with constant ductility spectra. The obtained values need, however, further validation based on experimental and analytical data.

\section{ACKNOWLEDGEMENTS}

This research was sponsored by NATO's Scientific Affairs Division in the framework of the Science for Peace Programme, project SfP-980468.

\section{REFERENCES}

Bozorgnia, Y., Bertero, V. V. (2001). Improved shaking and damage parameters for post-earthquake applications. Proceedings of the SMIP01 Seminar on Utilization of Strong-Motion Data, Los Angeles, California, September 12, 1-22.

Cosenza, E., Manfredi, G., Ramasco, R. (1993). The use of damage functionals in earthquake engineering: a comparison between different methods. Earthquake Engineering and Structural Dynamics, 22, 855-868.

Craifaleanu, I. G. (2001). Characterisation of seismic response using damage indices, Buletinul AICPS, $12: 2$. 71-79 (in Romanian).

Craifaleanu, I. G. (2005). Nonlinear Single-Degree-of Freedom Models in Earthquake Engineering, Matrix Rom Publishers, Bucharest (in Romanian).

Craifaleanu, I. G., Lungu, D., Borcia, I. S. (2006). Shakemaps of nonlinear spectral ordinates for Vrancea earthquakes, Proceedings of the First European Conference on Earthquake Engineering and Seismology, Geneva, Switzerland, 3-8 September. Paper No.1257 (on CD-ROM).

Lungu, D., Aldea, A., Demetriu, S., Craifaleanu, I. (2004). Seismic strengthening of buildings and seismic instrumentation - two priorities for seismic risk reduction in Romania. Acta Geodaetica et Geophysica Hungarica, 39:2-3, 233-258.

Lungu, D., Craifaleanu, I. G., Borcia, I. S., (2005). Zoning of the characteristics of Vrancea earthquakes and of their effect on buildings. Proceedings on the Third National Conference of Earthquake Engineering, Bucharest, December 9. Vol. 1, 53-68 (in Romanian).

Lungu, D., Craifaleanu, I. G. (2007). Spatial distribution of strength and displacement demands for Romanian earthquakes, Proceedings of the International Symposium on Seismic Risk Reduction, The JICA Technical Cooperation Project in Romania, Bucharest, April 26-27. 407-412, Paper ID: 79.

Fajfar, P. (1992). Equivalent ductility factors, taking into account low-cycle fatigue. Earthquake Engineering and Structural Dynamics. 21:10, 837-848.

Mahin, S. A., Lin, J. (1983). Construction of Inelastic Response Spectra for Single-Degree-of-Freedom Systems: Computer Program and Applications. Report No. UCB/EERC-83/17. Earthquake Engineering Research Center, University of California, Berkeley, California.

Park, Y.-J., Ang, A. H.-S. (1985). Mechanistic seismic damage model for reinforced concrete. Journal of Structural Engineering, 111:4, 722-739.

Teran-Gilmore, A. (1996). Performance-Based Earthquake-Resistant Design of Framed Buildings Using Energy Concepts. Ph.D. Thesis. University of California, Berkeley.

Seismic Database for Romanian Earthquakes (2001). National Institute for Building Research, INCERC, and National Institute for Earthquake Physics, NIEP. Research founded by the Romanian Ministry of Education and Research. 